DOI: 10.12731/2658-6649-2019-11-5-2-56-61

УДК 616.12-008.331.1:616.13-053.81

\title{
СКОРОСТЬ РАСПРОСТРАНЕНИЯ ПУЛЬСОВОЙ ВОЛНЫ КАК ФАКТОР РИСКА РАЗВИТИЯ СЕРДЕЧНО-СОСУДИСТЫХ ЗАБОЛЕВАНИЙ В МОЛОДОМ И СРЕДНЕМ ВОЗРАСТЕ
}

Кочергина К.Н., Яскевич Р.А., Каспаров Э.В.

Представлены результаты изучения эластических свойств артерий у 58 людей молодого возраста и 81 человека среднего возраста обоего пола. Использовались показатели скорости распространения пульсовой волны, а также модулей упругости сосудов эластического и мышечного типа. Анализ показал, что пациенты с артериальной гипертонией 1 степени среднего возраста имели более высокие показатели как в своей группе, так и в сравнении с группой молодого возраста, однако статистически значимой разницы между группами выявлено не было.

Ключевые слова: скорость распространения пульсовой волны; эластичность артерий; артериальная гипертония.

\section{PULSE WAVE VELOCITY AS A RISK FACTOR FOR DEVELOPMENT OF CARDIOVASCULAR DISEASE IN YOUNG AND MIDDLE AGE}

\author{
Kochergina K.N., Yaskevich R.A., Kasparov E.V.
}

The results of the study of elastic properties of arteries in 58 young people and 81 middle-aged people of both sexes are presented. Used indicators of the propagation velocity of the pulse wave and moduli of elasticity of the blood vessels elastic and muscular type. The analysis showed that patients with arterial hypertension of the 1st degree of middle age had higher rates both in their group and in comparison with the group of young age, but there was no statistically significant difference between the groups.

Keywords: pulse wave velocity; arterial elasticity; arterial hypertension. 


\section{Введение}

В настоящее время отмечается широкая распространенность артериальной гипертонии (АГ) среди людей среднего возраста и рост заболеваемости среди молодых людей $[1$, c. 45,2, с. 181]. При этом нужно учитывать, что до клинически явной АГ следует стадия латентных нарушений сердечно-сосудистой системы [6, с. 26]. Традиционными факторами кардиоваскулярного риска являются возраст, пол, АГ, курение, гипергликемия и дислипидемия $[5$, с. 41,7, с. 86$]$. Важную роль в развитии многих заболеваний сердечно-сосудистой системы играет снижение эластичности и повышение жесткости стенки крупных артерий [4, с. 3, 3, с. 31]. Перспективным параметром для определения доклинических нарушений структурно-функциональных свойств сосудистой жесткости на ранних этапах является скорость распространения пульсовой волны (СРПВ) с целью профилактики сосудистых катастроф [3, с. 31, 6, с. 26].

\section{Цель}

Изучить особенности показателей жесткости артерий у лиц молодого и среднего возраста в зависимости от половой принадлежности, курения, индекса массы тела (ИМТ), уровня артериального давления (АД).

\section{Материалы и методы исследования}

Исследование скорости распространения пульсовой волны (СРПВ) по сосудам эластического типа (СРПВэ) и мышечного типа (СРПВм), а также модулей упругости сосудов эластического (Еэ) и мышечного типа (Ем) было проведено у 58 пациентов молодого возраста, средний возраст 20,6 лет, и 81 пациента среднего возраста, средний возраст 54,8 года, с помощью сфигмографической приставки «Полиспектр-12».

\section{Результаты и обсуждение}

В ходе исследования установлено, что среди пациентов молодого возраста статистически значимое увеличение показателей СРПВэ наблюдалось у лиц мужского пола $7,78[6,72-8,9]$ м/с, в отличие от лиц женского пола $6,4[5,2-8,51] \mathrm{m} / \mathrm{c}(\mathrm{p}=0,03)$. Значения СРПВэ и СРПВм сохраняли тенденцию к увеличению в группе среднего возраста как у мужчин, так и у женщин. Показатель СРПВм/СРПВэ оказался выше у девушек 1,25 $[1,07-1,42]$ в отличие от аналогичного показателя у женщин среднего возраста 1,02 [0,87 - 1,12] ( $\mathrm{p}=0,001)$. Показатель Ем/Еэ среди женщин так же был выше у лиц молодого возраста $1,03[0,75-1,33]$ в сравнении со 
средним возрастом 0,68 [0,5 - 0,83] ( $\mathrm{p}=0,001)$. Среди курящих пациентов разного возраста достоверных отличий не отмечено. В группах некурящих пациентов имелась тенденция к увеличению показателей СРПВэ, СРПВм/СРПВэ и Еэ у пациентов среднего возраста $(\mathrm{p}=0,001)$. Среди лиц молодого возраста с АГ 1 степени показатели СРПВэ 8,91 [7,10 - 10,94] м/с и Еэ 10,73 [6,81 - 16,17] м/с были выше, чем аналогичные у молодых людей с высоким нормальным уровнем АД - СРПВэ 7,87 [6,41 - 8,18] м/с и Еэ 8,37 [5,55 - 9,04] м/с. У пациентов с АГ 1 степени выявлено увеличение СРПВ в артериях преимущественно эластического типа у пациентов средней возрастной группы 9,32 [8,48 - 10,47] м/с по сравнению с молодыми пациентами 8,91 [7,10 - 10,94] м/с, а также более высокие показатели модуля упругости сосудов эластического типа (Еэ) в группе среднего возраста 11,74 [9,72 - 14,81] тыс.дин/см² , чем аналогичный показатель у молодых людей 10,73 [6,81 - 16,17] тыс.дин/см². Оценивая особенности показателей эластичности сосудов у лиц с избыточной массой тела можно отметить увеличение показателя СРПВэ 8,75 м/с и Еэ 10,35 м/с у пациентов среднего возраста $(\mathrm{p}=0,003)$.

\section{Заключение}

Анализ СРПВ и модулей упругости сосудов эластического и мышечного типа у пациентов разных возрастных групп показал влияние таких характеристик, как возраст, мужской пол, курение, уровень АД, избыточная масса тела на эти показатели, что поможет в оценке кардиоваскулярного риска.

\section{Список литературы}

1. Брянцева Е.Н., Горбунов В.В., Губанова М.В. Динамика показателей центрального аортального давления и скорости распространения пульсовой волны при гипертонической болезни I стадии у молодых мужчин // Сибирский медицинский журнал. 2015. №1. С. 45-48.

2. Докина Е.Д., Шашина Н.Б., Бабанин В.С. и др. Исследование артериальной жесткости в амбулаторной практике у лиц трудоспособного возраста // Российский медицинский журнал. 2017. №4. С. 181-184.

3. Олейников В.Э., Хромова А.А., Бурко Н.В. и др. Комплексная оценка показателей ригидности артерий и традиционных факторов риска как предикторов синдрома раннего сосудистого старения // Российский кардиологический журнал. 2018. №3. С. 31-36.

4. Разумов А.Н., Бобровницкий И.П., Колесникова И.В. и др. Влияние электромагнитных полей на тонус церебральных сосудов и артериальное дав- 
ление // Вопросы курортологии, физиотерапии и лечебной физической культуры. 2006. № 2. С. 3-5.

5. Ризванова Р.Т., Максимов Н.И. Ремоделирование сосудов у молодых пациентов с артериальной гипертонией и метаболическим синдромом // Практическая медицина. 2016. №9 (101). С. 41-43.

6. Хурса Р.В. Дисфункциональные типы кровообращения у практически здоровых молодых людей: особенности функционального состояния сосудов и центральной гемодинамики // Международный журнал сердца и сосудистых заболеваний. 2018. Т. 6, №17. С. 26-35.

7. Яскевич Р.А. Характеристики пульсовой волны у слабослышащих мигрантов крайнего севера старших возрастных групп // Клиническая геронтология. 2018. Т. 24, № 9-10. С. 86-88.

\section{References}

1. Bryantseva E.N., Gorbunov V.V., Gubanova M.V. Dinamika pokazatelej tsentral'nogo aortal'nogo davleniya i skorosti rasprostraneniya pul'sovoj volny pri gipertonicheskoj bolezni I stadii u molodykh muzhchin [Dynamics of Central aortic pressure and pulse wave propagation velocity in hypertensive disease of the first stage in young men] // Sibirskij meditsinskij zhurnal [Siberian medical journal]. 2015. №1. S. 45-48.

2. Dokina E.D., Shashina N.B., Babanin V.S. i dr. Issledovanie arterial'noj zhestkosti $v$ ambulatornoj praktike $u$ lits trudosposobnogo vozrasta [Study of arterial stiffness in outpatient practice in persons of working age] // Rossijskij meditsinskij zhurnal [Russian medical journal]. 2017. №4. S. 181-184.

3. Olejnikov V.Eh., Khromova A.A., Burko N.V. i dr. Kompleksnaya otsenka pokazatelej rigidnosti arterij i traditsionnykh faktorov riska kak prediktorov sindroma rannego sosudistogo stareniya [Comprehensive assessment of indices of arterial stiffness and traditional risk factors as predictors of the syndrome of early vascular aging] // Rossijskij kardiologicheskij zhurnal [Russian cardiology journal]. 2018. №3. S. 31-36.

4. Razumov A.N., Bobrovnickij I.P., Kolesnikova I.V. i dr. Vliyanie elektromagnitnyh polej na tonus cerebral'nyh sosudov i arterial'noe davlenie [The influence of electromagnetic fields on the tone of cerebral vessels and blood pressure] // Voprosy kurortologii, fizioterapii i lechebnoj fizicheskoj kul'tury [Questions of balneology, physiotherapy and physical culture]. 2006. № 2. S. 3-5.

5. Rizvanova R.T., Maksimov N.I. Remodelirovanie sosudov u molodykh patsientov s arterial'noj gipertoniej i metabolicheskim sindromom [Vascular remodeling in young patients with arterial hypertension and metabolic syndrome] // Prakticheskaya meditsina [Practical medicine]. 2016. №9 (101). S. 41-43. 
6. Khursa R.V. Disfunktsional'nye tipy krovoobrashheniya u prakticheski zdorovykh molodykh lyudej: osobennosti funktsional'nogo sostoyaniya sosudov i tsentral'noj gemodinamiki [Dysfunctional types of blood circulation in healthy young people: features of the functional state of blood vessels and central hemodynamics] // Mezhdunarodnyj zhurnal serdtsa i sosudistykh zabolevanij [International journal of heart and vascular diseases]. 2018. T. 6, №17. S. 26-35.

7. Yaskevich R.A. Harakteristiki pul'sovoj volny u slaboslyshashchih migrantov krajnego severa starshih vozrastnyh grupp [Characteristics of the pulse wave in hearing impaired migrants of the far north of the older age groups] // Klinicheskaya gerontologiya [Clinical gerontology]. 2018. T. 24, № 9-10. S. 86-88.

\section{ДАННЫЕ ОБ АВТОРАХ}

Кочергина Ксения Николаевна, студентка 6 курса Лечебного факультета КрасГМУ им. проф. Ф.В. Войно-Ясенецкого ГБОУ ВПО «КрасГМУ им. проф. Ф.В. Войно-Ясенеикого» МЗ РФ ул. Партизана Железняка, 1а, г. Красноярск, 660022, Российская Федераиия

ko4ergina.ksen@gmail.com

Яскевич Роман Анатольевич, доцент кафедры пропедевтики внутренних болезней и терапии, ведущий научный сотрудник, кандидат медицинских наук, доцент

ГБОУ ВПО «КрасГМУ им. проф. Ф.В. Войно-Ясенеикого» МЗ РФ; Федеральное государственное бюджетное научное учреждение «Научно-исследовательский институт медиџинских проблем Севера»

ул. Партизана Железняка, 1а, г. Красноярск, 660022, Российская Федерачия; ул. Партизана Железняка, 32, г. Красноярск, 660022, Российская Федерация cardio@impn.ru

Каспаров Эдуард Вильямович, д.м.н., профессор, директор НИИ МПС ФИЦ КНЦ СО РАН, зам. директора ФГБНУ «Федеральный исследовательский центр «Красноярский научный центр СО РАН» Научно-исследовательский институт медицинских проблем Севеpa, Федеральное государственное бюджетное научное учреждение «Федеральный исследовательский иентр «Красноярский научный иентр Сибирского отделения Российской академии наук» 
ул. Партизана Железняка, 32, г. Красноярск, 660022, Российская Федераиия impn@impn.ru

\section{DATA ABOUT THE AUTHORS}

Kochergina Ksenia Nikolaevna, 6th year student of the Medical faculty Krasnoyarsk State Medical University named after Professor V.F. Voino-Yasenetzkiy

1a, P. Zheleznyaka St., Krasnoyarsk, 660022, Russian Federation ko4ergina.ksen@gmail.com

Yaskevich Roman Anatolyevich, associate professor at department of propedeutics of internal diseases and therapy, leading researcher, candidate of medical science, docent

Krasnoyarsk State Medical University named after Professor V.F. Voino-Yasenetzkiy; Federal State Budgetary Scientific Institution «Scientific Research Institute of medical problems of the North» 1a, P. Zheleznyaka St., Krasnoyarsk, 660022, Russian Federation; 3g, Partizan Zheleznyaka str., Krasnoyarsk, 660022, Russian Federation cardio@impn.ru

Kasparov Eduard Vilyamovich, MD, professor, Director

Scientific Research Institute of medical problems of the North, Federal Research Center "Krasnoyarsk Science Center» of the Siberian Branch of the Russian Academy of Sciences 3d, P. Zheleznyaka St., Krasnoyarsk, 660022, Russian Federation impn@impn.ru 